\title{
Experiencias de movilidad residencial en jóvenes de barrios populares de Buenos Aires (Argentina)
}

\author{
Experiences of residential mobility in young people from \\ working class neighbourhoods in Buenos Aires (Argentina) \\ Experiências de mobilidade residencial em jovens de bairros \\ populares de Buenos Aires (Argentina)
}

Silvia Alejandra Tapia*

\section{RESUMEN}

Las investigaciones sociales comenzaron a visibilizar las expe-

Palabras clave: riencias de movilidad migratoria y urbana de jóvenes en Latinoexperiencia, américa, sin embargo sus movilidades residenciales aún tienen hogar, juventudes, escasa atención. Retomando el nuevo paradigma de las movilimovilidad dades y la sociología de la experiencia, problematizo abordajes residencial. transicionales y analizo las experiencias de movilidad residencial de jóvenes de barrios populares de la Región Metropolitana de Buenos Aires (Argentina). Indago significaciones construidas sobre el hogar y sus (in)movilidades, advirtiendo los procesos de fragmentación urbana y desigualdad social de las ciudades latinoamericanas. Desde una estrategia cualitativa, a partir de entrevistas en profundidad, analizo los datos empíricos siguiendo la perspectiva constructivista de la teoría fundamentada. Surgieron categorías asociadas a experiencias de (in)movilidad residencial, identificadas como forzosas, buscadas e imaginadas. Se tensionan las significaciones acerca de lo juvenil en vinculación con procesos urbanos y sociales, condiciones familiares e institucionales, la conformación y uso de los hogares o los barrios en los que se ubican, desde un análisis centrado en el reconocimiento de las experiencias juveniles.

\footnotetext{
* Argentina. Dra. en Ciencias Sociales. Consejo Nacional de Investigaciones Científicas y Técnicas (CONICET) e Instituto de Investigaciones Gino Germani, Facultad de Ciencias Sociales, Universidad de Buenos Aires. Buenos Aires, Argentina. stapia@ sociales.uba.ar
} 


\begin{abstract}
Social research has begun to make the experiences of migratory and urban mobility of young people in Latin America visible, but their residential mobility still receives little attention. Taking up the new paradigm of mobilities and the sociology of experience, I problematize transitional approaches and analyses the experiences of residential mobility of young people from working class neighborhoods in the Metropolitan Region of Buenos Aires (Argentina). I investigate the meanings constructed about the home and its (in)mobilities, noting the processes of urban fragmentation and social inequality in Latin American cities. From a qualitative strategy, based on in-depth interviews, I analyze the empirical data following the constructivist perspective of grounded theory. Categories associated with experiences of residential (in)mobility emerged, identified as forced, sought and imagined. The meanings of youth in relation to urban and social processes, family and institutional conditions, the conformation and use of the homes or neighborhoods in which they are located, from an analysis centered on the recognition of youth experiences.
\end{abstract}

\section{RESUMO}

As pesquisas sociais começaram a tornar visíveis as experiências de mobilidade migratória e urbana de jovens na América Latina. Porém, a mobilidade residencial ainda recebe pouca atenção. Retomando o novo paradigma das mobilidades e a sociologia da experiência, problematizo abordagens transicionais e analiso as experiências de mobilidade residencial de jovens de bairros populares da Região Metropolitana de Buenos Aires (Argentina). Questiono os significados construídos sobre o lar e suas (i)mobilidades, advertindo os processos de fragmentação urbana e desigualdade social das cidades latino-americanas. A partir de uma estratégia qualitativa, baseada em entrevistas aprofundadas, analiso os dados empíricos seguindo a perspectiva construtivista da teoria fundamentada. Surgiram categorias associadas a experiências de (i)mobilidade residencial, identificadas como forçadas, procuradas e imaginadas. São tensionadas as significações sobre a juventude em relação aos processos urbanos e sociais, às condições familiares e institucionais, à conformação e ao uso dos lares ou dos bairros em que estão localizados, a partir de uma análise focada no reconhecimento das experiências juvenis.
Keywords:

experience, home, youth, residential mobility.

Palavras-chave: experiência, lar, juventudes, mobilidade residencial. 


\section{Introducción}

En los últimos años los desplazamientos de jóvenes latinoamericanos comenzaron a tener mayor atención en indagaciones acerca de procesos migratorios (Rodríguez y Dawkins, 2017; Varela Huerta, 2015), así como respecto de los usos y apropiaciones del espacio público, por ejemplo, desde lo artístico (Diógenes, 2020) o lo político (Urzúa Martínez, 2015). Estos abordajes señalan que la fragmentación y las desigualdades socioespaciales presentes en las urbes latinoamericanas, así como la segmentación en el acceso a recursos, tienen implicancias significativas en las movilidades juveniles (Bastán y Paulín, 2016; Chaves y Segura, 2015).

Las movilidades residenciales se encuentran en estrecha relación con las migratorias y urbanas (Di Virgilio y Gil y de Anso, 2012), sin embargo es escasa la atención a las primeras en los estudios referentes a juventudes en América Latina. Pueden destacarse, no obstante, los trabajos de Soto (2017) en torno a la elección de la ubicación en las movilidades residenciales de estudiantes de nivel superior de Valparaíso, Chile. Asimismo, Arancibia (2016) y Felice (2017), ambas en Argentina, que desde la sociología de la transición abordan, la primera, trayectorias habitacionales y su relación con trayectorias laborales juveniles de distintos sectores sociales y, la segunda, experiencias de conformación del hogar propio en jóvenes de sectores medios.

En cambio, existe una importante producción académica desarrollada en países del norte relativos jóvenes y movilidades residenciales. Dichos estudios interrogan acerca de las razones que impulsan tales desplazamientos, su frecuencia, desde y hacia qué lugares se orientan, quiénes se mueven o permanecen, observando cómo los procesos de exclusión social y segregación residencial afectan de manera desigual a distintos sectores sociales (Baker et al., 2019; Brazil y Clark, 2019).

$\mathrm{Al}$ abordar los impactos de las movilidades residenciales en las vidas de jóvenes dichas investigaciones estudian, fundamentalmente, tres dimensiones: acceso, continuidad y rendimiento escolar (Metzger et al., 2015; Schmitt y Lipscomb, 2016), problemáticas de salud y bienestar socioemocional - como consumo de drogas, embarazo adolescente o depresión- (Cotton y Schwartz-Barcott, 2016; Lara et al., 2016), y el sostenimiento o pérdida de redes sociales, familiares e institucionales (Goodman et al., 2018; Tønenssen et al., 2016). 
Estas indagaciones siguen las perspectivas de ciclo de vida (life course) y de la sociología de la transición. En la primera, predominan los análisis retrospectivos que rastrean cómo afectan en la vida adulta las movilidades experimentadas en la niñez (Falkingham et al., 2016). En la segunda, se plantean ciertos eventos biográficos como disparadores de otros eventos significativos. Momentos de búsqueda de mayor independencia como salir del hogar materno/paterno, conformar pareja o ingresar a la universidad o a un nuevo trabajo, llevarían a constituir nuevos hogares o explorar otros lugares para vivir (Hochstenbach y Boterman, 2017).

Las miradas críticas advierten en estas perspectivas transicionales visiones estáticas y adultocéntricas de lo juvenil. Si bien algunas versiones reconocen posibles discontinuidades producto de las transformaciones sociales de las últimas décadas que han desestandarizado e individualizado las trayectorias, prevalece la noción de etapas comunes por atravesar hacia la adultez (Coulter et al., 2015; Roberti, 2017). Se sustentan, asimismo, en una idea de emancipación como evento necesario para impulsar movilidades residenciales. Así, estas investigaciones presentan experiencias basadas en una independencia personal donde, por ejemplo, el retorno por dificultades económicas o rupturas de parejas son entendidas como irregularidades. En consecuencia, la idea de transición a la adultez no permite vislumbrar la diversidad y el carácter procesual de las movilidades residenciales que atraviesan las biografías juveniles. Si bien no son independientes del grupo familiar, para los y las jóvenes suponen la construcción de prácticas y significaciones propias (Padilla, 2017).

Propongo interpelar tales visiones homogeneizadoras de lo juvenil y de los desplazamientos como eventos únicos, previsibles o lineales. En mi investigación doctoral (Tapia, 2016), siguiendo los aportes de la sociología del individuo de Danilo Martuccelli (Araujo y Martuccelli, 2010), analicé las experiencias de jóvenes de barrios populares de la Región Metropolitana de Buenos Aires (RMBA), Argentina, que participaban en un circo social. Identifiqué las pruebas más significativas en sus relatos biográficos, así como el trabajo realizado sobre sí mismos y los soportes movilizados para enfrentarlas. Desde los emergentes "salir-estar", en diálogo con la bibliografía, construí la categoría: prueba de las movilidades. Esta evocaba desafíos presentes en sus desplazamien- 
tos migratorios, residenciales y urbanos que configuraban distintas geometrías de vulnerabilidad. En un proyecto en curso, continuando tales indagaciones, estudio las experiencias de jóvenes en su vínculo con instituciones educativas en tales barrios, desde las intersecciones entre (in)movilidades, cuerpos/emociones y desigualdades sociales.

Cabe señalar que la RMBA es la región central del país que abarca la Ciudad Autónoma de Buenos Aires (CABA) —núcleo de la RMBA, en términos administrativos, económicos, laborales, de consumo, de ocio, salud y educación (Cosacov, 2015) - y el Gran Buenos Aires (GBA), compuesto por 15 municipios con gran heterogeneidad económica y social en su interior. Allí conviven, paradójicamente, políticas neoliberales de privatización y desregulación del uso del suelo urbano con políticas orientadas a redistribuir los ingresos. Como resultado, la región expresa una fragmentación territorial donde predomina una diferenciación a pequeña escala — por sobre las tradicionales separaciones centro/periferia- que sostiene formas de segregación urbana, educativa y social en su interior. Presenta, además, importantes dificultades en el acceso a la vivienda para los sectores sociales de menor nivel socioeconómico, los que muchas veces recurren al mercado informal y a condiciones precarizadas de vida (Di Virgilio, 2018; Segura, 2017).

En tal contexto, las y los entrevistados experimentaron múltiples movilidades residenciales. Si bien no era objetivo específico de la investigación abordarlas, estas emergieron como significativas al relatar la llegada y participación en las instituciones estudiadas. Para su análisis planteé como pregunta-problema que guía este artículo: ¿Qué experiencias construyen las y los jóvenes de barrios populares de la RMBA en y desde las prácticas de (in)movilidad residencial y qué significaciones de hogar producen en torno a aquellas, en un contexto de desigualdad social y fragmentación urbana de la región?

Retomando los aportes del nuevo paradigma de la movilidad (Sheller y Urry, 2006) y la sociología de la experiencia social (Dubet, 2013), analizo las experiencias de (in)movilidad residencial de jóvenes de barrios populares de la RMBA, explorando las significaciones que construyen acerca del hogar y tales (in)movilidades, en un marco de desigualdad y fragmentación urbana. Parto del supuesto de que las (in) movilidades residenciales juveniles no se limitan a la transición a la 
adultez y que, en un contexto de singularización de las sociedades, indagar las experiencias permite advertir el trabajo que realizan las personas jóvenes para integrar estrategias, reflexividades y pautas sociales en diálogo con las tramas e intersticios de los procesos urbanos.

El presente artículo se organiza de la siguiente manera: primero, se exponen brevemente las herramientas conceptuales propuestas. Segundo, se presenta la estrategia metodológica seguida para la construcción y análisis de los datos empíricos. Tercero, se presentan los resultados, distinguiendo las tres dimensiones emergentes acerca de las experiencias de movilidad residencial juvenil: forzosas, buscadas e imaginadas. En la discusión y conclusiones, se articulan tales dimensiones a partir de la noción de experiencias y sus lógicas de acción, reflexionando acerca de las tensiones en la comprensión de lo juvenil, las (in)movilidades urbanas y los hogares, la fragmentación urbana y las desigualdades sociales.

\section{Juventudes, experiencias e (in)movilidades: herramientas conceptuales}

A diferencia de los discursos que conciben la juventud como un período vital homogéneo o como seres en transición de la niñez a la adultez (Chaves, 2005), se entiende a las juventudes desde su complejidad y pluralidad. Dicha clasificación social alude a una construcción sociohistórica y cultural que la distingue de otros actores sociales y pone de manifiesto disputas en torno a su definición y caracterización. Lo juvenil requiere, por tanto, un análisis situado y relacional para reconocer el modo en que cada sociedad segmenta e institucionaliza lo etario (Chaves, 2013; Duarte Quapper, 2000; Muñoz y Ponce, 2019).

Los abordajes lineales sustentados en una imagen de sociedad estable y coherente encuentran limitaciones frente a las transformaciones de las sociedades contemporáneas - mayor complejidad, heterogeneidad e individualización- que expresan modos de ser joven no determinados por posiciones sociales, pero tampoco por individuos plenamente libres y autónomos. Como señalan Araujo y Martuccelli (2011), la diversidad de experiencias entre actores sociales está asociada con los diferentes procesos estructurales que operan en la producción de los individuos en diálogo con los márgenes de agencia con los que estos cuentan. 
Para analizar tales articulaciones son necesarias herramientas conceptuales que trasciendan las versiones dicotómicas de lo social (Di Leo y Camarotti, 2013). En ese sentido, la noción de experiencia propuesta por Dubet (2013) recupera la visión subjetiva de lo social. Esto no supone "renunciar al análisis de los procesos y mecanismos sociales, sino de reconstruirlos desde el nivel de las experiencias, las lógicas de acción y las interacciones de los individuos" (Martinic y Stecher, 2020, p. 7).

Ante la paradoja de una acción que es social y, a la vez, de individuos que actúan y toman decisiones, el concepto de experiencia permite comprender las vinculaciones entre las maneras en que los individuos son producidos, cómo perciben y construyen lo social y a sí mismos, desde la articulación de tres lógicas de acción (Dubet, 2013; Martinic y Stecher, 2020):

a) integración: interiorizar mecanismos y normas sociales derivados de valores colectivos, creando pertenencias y arbitrando diversos roles (de género, etarios, familiares, entre otros) que definen cómo actuar.

b) estrategia: movilizar medios y recursos orientados por objetivos en el marco de diferentes interacciones sociales.

c) subjetivación: capacidades de los actores para conformar una perspectiva singular y crítica, que se distingue de lo normativo y sus estrategias, sobre sí mismos y el mundo social.

Por su parte, atendiendo a las vinculaciones entre subjetividades y estructuras, el nuevo paradigma de la movilidad - mobility turn(Sheller y Urry, 2006), como enfoque (Jirón e Imilán, 2018), observa las posibles intersecciones entre movilidades e inmovilidades de personas, objetos, información, imágenes, entre otros. Entiende las inmovilidades no como meras resultantes de la falta de movilidad, sino como procesos activos, deseados o forzados (Coulter et al., 2015).

Hablar de (in)movilidades no significa priorizar lo móvil o veloz por sobre lo fijo y permanente. Este enfoque no asocia la movilidad con una mayor libertad desde miradas romantizadas de los desplazamientos (Salazar, 2020). Rastrea las formas en que ciertas movilidades son reguladas, limitadas - por restricciones legales, económicas o simbó- 
licas - mientras otras son permitidas, impulsadas o deseadas (Salazar y Smart, 2011). Busca identificar las diferentes capacidades de ser móviles - o bien, de ser inmóviles, de permanecer- que despliegan los actores, las que se presentan distribuidas de manera desigual entre distintos grupos sociales (Kaufmann et al., 2004).

Este giro a la movilidad advierte acerca de las múltiples interconexiones entre lo material y lo simbólico, lo practicado y lo imaginado ${ }^{1}$. Desde una mirada relacional, de acuerdo con Jirón e Imilán (2018), este giro permite:

construir objetos de estudio desde múltiples relaciones, en consideración de movimientos y ritmos en la ciudad y el territorio. Estas relaciones no son estáticas, ni locales o aisladas, sino que son complejas y multiescalares (Freire y Allis 2018). Las investigaciones han demostrado cómo las formas de habitar en movimiento se vinculan desde el cuerpo hasta la forma en que las decisiones sobre la ciudad se toman a nivel global. (p. 19).

Recuperando estos aportes entiendo las movilidades residenciales desde las articulaciones entre movilidades e inmovilidades intraurbanas, entre diferentes viviendas -incluso de manera simultánea-, las significaciones, prácticas y relaciones asociadas a estas, así como las distintas formas de habitar ${ }^{2}$ que provocan, a su vez, transformaciones en las distintas áreas de la ciudad. No suponen simples desplazamientos de un lugar de origen a uno de destino, sino procesos relacionales y prácticas activas (Coulter et al., 2015; Cresswell, 2010; Di Virgilio, 2011).

Asimismo, problematizando las nociones sedentaristas, limitadas a una ubicación fija y permanente, recupero la noción de hogar como una experiencia dinámica, posible de generarse en la movilidad. Sin ser considerado a priori como eventos desestabilizadores o negativos,

1 La imaginación no supone una fantasía frente a una realidad preexistente o algo externo a las prácticas sociales, sino una "práctica corporizada que trasciende las distancias físicas y socioculturales. Aun cuando una persona pueda permanecer en un lugar, su imaginación puede estar en movimiento, viajando a otros lugares y a otras temporalidades" (Rapport y Dawson, 1998 en Salazar, 2020, p. 6; traducción propia).

2 Como señala Cervio (2020), siguiendo a Lefevbre, "habitar es apropiarse del espacio, convirtiéndolo en lugar. Es adaptar, usar, transformar y verter en el espacio la afectividad del usuario, la imaginación del habitante" (p. 339). 
se observan las (in)movilidades residenciales en relación con la creación de hogares en movimiento (Buckle, 2017; Jirón e Imilán, 2018).

\section{Metodología}

En este artículo presento los resultados de una investigación doctoral finalizada (2014-2016) y los avances de un proyecto en curso (2017 a la actualidad). Ambos estudios siguen una estrategia cualitativa interpretativa que, desde un diseño abierto y flexible, busca "comprender el sentido de la acción social en el contexto del mundo de la vida y desde la perspectiva de los participantes" (Vasilachis, 2012, p. 48). Dicho abordaje se interesa por cómo el mundo social es producido y comprendido, entendiendo que la realidad es construida por sujetos activos. Indaga acerca de las interacciones sociales, prácticas y significaciones atendiendo, al mismo tiempo, a los contextos en que se producen y a la dinámica de los procesos en los que se despliegan.

Para la construcción de datos empíricos realicé entrevistas en profundidad ${ }^{3}$, herramienta de carácter comunicativo que produce una situación social en la que interactúan dos personas para obtener descripciones e interpretaciones de ciertos fenómenos. Descentrando el lugar de quien investiga, habilita una forma de conocimiento que busca captar los significados atribuidos por los actores a su propia experiencia en ese contexto de interacción social que supone la entrevista (De Sena et al., 2015; Merlinsky, 2006). Los significados no son tratados como hechos puros, sino como productos sociales modificados en cada interacción. Por ello, se consideran:

mediados por la construcción que hacen los propios sujetos en base a su experiencia. Cuando nos proponemos atrapar el significado que los otros atribuyen a sus propias prácticas debemos asumir que "nuestro conocimiento del mundo supone un conjunto de abstracciones, generalizaciones, formalizaciones e idealizaciones propias del nivel respectivo de organización del pensamiento. En términos estrictos, los hechos puros y simples no existen, por consiguiente se trata siempre de hechos interpretados". (Schutz 1995 en Merlinsky, 2006, pp. 28-29).

3 En la tesis doctoral se construyeron relatos biográficos a partir de las entrevistas, siguiendo los aportes de Leclerc-Olive (2009) y Di Leo y Camarotti (2013). 
Para la conformación de la muestra, de tipo intencional (Vasilachis, 2012), busqué diversificar por género, edad, barrio de residencia, tipo de actividad realizada y tiempo en la institución. Entrevisté a 26 jóvenes, de entre 14 y 24 años, que participaran de espacios institucionales con ofertas de actividades artísticas, formativas y educativas gratuitas que, en investigaciones previas, había identificado como significativas en las vidas de los y las jóvenes (referencia anonimizada), en este caso: dos escuelas secundarias públicas, dos bachilleratos populares ${ }^{4}$, una cooperativa de trabajo ${ }^{5}$ y un circo social ${ }^{6}$. Las instituciones seleccionadas están ubicadas en áreas de vulnerabilidad social y educativa $(\mathrm{RMBA})^{7}$. En el trabajo de campo, el análisis y en la presentación de los datos tomé los resguardos éticos correspondientes, contemplando el anonimato y la confidencialidad.

En el procesamiento y análisis de las entrevistas seguí los lineamientos de la perspectiva constructivista de la teoría fundamentada (Charmaz y Belgrave, 2012). A diferencia de las versiones objetivistas de la teoría fundamentada, esta perspectiva "no supone que los datos simplemente estén a la espera de ser descubiertos en el mundo exterior (...) ni tampoco supone que los observadores imparciales ingresen en la escena de la investigación sin un marco de referencia interpretativo" (Charmaz, 2013, p. 276).

La teoría fundamentada, como método comparativo, se basa en la construcción y lectura de información a través de comparar datos con datos y codificarlos. En este caso, utilicé como soporte el software ATLAS.ti 7. Al codificar las entrevistas identifiqué las categorías emergentes - considerando las dimensiones conceptuales relevantes para el estudio, pero sin limitarme a ellas-y registré los puntos en común y discontinuidades entre los datos vinculados con procesos de movilidad residencial y construcción de hogares. Nombrados por las y los

4 Espacios creados por organizaciones sociales - algunas con reconocimiento estatal- que brindan escolarización secundaria gratuita para jóvenes y personas adultas (García, 2013).

5 Organización social que, con subsidio estatal, ofrece cursos de formación en oficios, espacios de recreación y refrigerios a jóvenes de barrios populares de la CABA.

6 Organización social que ofrece talleres de artes circenses - fundamentalmente por la participación en un programa municipal - cuyo propósito es contribuir a la transformación personal, comunitaria y social a través del arte.

7 Compartí el trabajo de campo de este proyecto con una investigación colectiva en la que participé (2016-2017), dirigida por el Dr. Pablo F. Di Leo. 
entrevistados como "mudanza/s" y "casa/s" (palabras utilizadas informalmente en Argentina). Esos datos fueron interpretados, rastreando conceptos teóricos asociados a dichas categorías para, a su vez, ser movilizados por estas.

Los emergentes estuvieron vinculados a prácticas y significaciones relacionadas con el modo en que las y los entrevistados han vivido procesos de (in)movilidad residencial: la búsqueda y sostenimiento de sus viviendas, la reconfiguración de sus hogares, las tensiones entre el presente y el pasado, las razones que atribuían a esas (in)movilidades, así como la relación con familiares, su entorno y su cotidianidad en tales procesos. De estos emergentes se distinguen tres dimensiones relevantes para comprender las experiencias juveniles respecto de sus movilidades residenciales:

a) forzosas: procesos ligados a circunstancias sociales, personales y económicas que se tornan problemáticas e impulsan búsquedas de nuevos lugares donde vivir. Se registran desde la niñez y hasta la actualidad. No son reconocidas como prácticas planeadas, ni responden al deseo de cambiar de lugar de residencia por parte de los y las jóvenes, o sus familias. En las entrevistas se menciona el "tener que" irse o "mudarse".

b) buscadas: procesos asociados a explorar mejores condiciones y nuevas oportunidades de vida. "Buscar" aparece asociado a alcanzar mejores condiciones de vida, obtener mayores oportunidades educativas y laborales, (re)encontrarse con familiares o convivir con una nueva pareja. Estas movilidades están estrechamente vinculadas con procesos migratorios de las y los entrevistados y sus familias.

c) imaginadas: procesos relacionados con proyectos de cambio en lo residencial esperados a futuro. Las y los jóvenes imaginan la construcción de hogares propios, los tipos de vivienda que podrían conseguir, con quienes las compartirían y los pasos que deberían recorrer para adquirirlas. Constituyen escenarios posibles que son imaginados y construidos desde y para el presente-futuro, en diálogo con lo ya vivido.

A continuación se presenta el análisis de tales dimensiones. 


\section{Resultados}

\section{Movilidades residenciales forzosas}

Situaciones asociadas a violencias, condiciones económicas o eventos que fueron reconocidos como problemáticos - como la muerte de un padre/madre o un embarazo no intencional en la adolescencia- llevaron a los y las jóvenes, en algunos casos con sus familias, a abandonar los lugares en los que residían, desconociendo hacia qué destinos o qué características tendrían los nuevos barrios o viviendas hacia donde se dirigían.

Cabe destacar el lugar de las violencias en lo narrado por las y los entrevistados. Se mencionan, particularmente, episodios de violencia familiar como acontecimientos significativos, en tanto giros existenciales que marcaron un antes y un después en sus vidas (Di Leo y Camarotti, 2013; Leclerc, 2009). Frente a estas violencias se producen separaciones o divorcios y la consecuente necesidad de desplazarse a nuevas viviendas.

Lulú, una de las entrevistadas, de 18 años, estudiante de la escuela secundaria de CABA, convive actualmente con su madre, hermano y abuela en un departamento alquilado en Caballito, barrio de nivel socioeconómico medio, situado en el centro geográfico de la ciudad (Cosacov, 2015). Su residencia en esta vivienda es reciente. Ella relata que, previamente, ha transitado por otros barrios junto con su familia. Ubica su primera vivienda en el GBA, en la zona oeste de la región metropolitana:

Yo nací en, bueno, de donde nací, nací en La Boca, pero me crie, más o menos, en mis primeros años de vida fue en Merlo o en Rodríguez, que queda en Moreno. Pasa que hubo un caso, más o menos, de violencia familiar. Mi papá se terminó yendo y mamá se quedó en Rodríguez con mi tío, yo y mi hermano. (Lulú, 18 años, escuela secundaria).

En su relato Lulú identifica que tras la violencia experimentada en la familia, su padre abandona el hogar y su madre, quien trabajaba en restaurantes de la CABA, comienza a sostenerlos económicamente. Debido a las largas distancias que esta debía recorrer para trabajar, optan por mudarse a un barrio más cercano "así ella llevaba más tiempo 
con nosotros". El traslado se realiza a una "pieza" [habitación] de un hotel en un barrio del sur de la ciudad, donde vivieron Lulú, su hermano, su abuela y su madre durante algunos años. Un barrio al que ella describe como "medio turbio", inseguro, que aun situado en un área céntrica, se caracteriza por ser una zona degradada de la ciudad (Toscani, 2018).

Comprender las violencias implica reconocer las complejas tramas histórico-sociales en las que se articulan dimensiones estructurales, institucionales y situacionales que afectan, de manera simbólica y material a los individuos (Di Leo, 2016). En el caso de Lulú expresadas en las vinculaciones entre las características del espacio urbano, las condiciones laborales y las violencias de género al interior de las familias se potencia un desplazamiento hacia un nuevo barrio y un tipo de vivienda marcados por la precariedad, aunque esto favorece la menor movilidad asociada al trabajo de su madre y mayor tiempo compartido.

Mateo, de 23 años, vive en una "villa" ${ }^{8}$ de la CABA con su madre. A los 6 años, su padre es denunciando por violencia familiar y por el abuso de una de sus hijas. En su relato, Mateo rememora el momento en que al salir de la escuela es llevado a una institución en la que viviría hasta sus 21 años:

Un gran cambio. Yo vivo y vivía acá en la villa 21, en Barracas, y desde los 6 años me fui, por problemas familiares, de maltrato, digamos, me mandaron a un instituto. Y yo viví toda mi vida en el instituto y en hogares (...) Era un paredón gigante, cuadrado, enorme, un cuadro de perímetro todo gigante, parecía una cárcel, pero era de chicos. Pero igual estuvo re bueno, digamos, porque salir de la villa a ir a un lugar un poco mejor y después de ahí, de la villa pasé a un instituto y del instituto pasé a un hogar [asilo infantil], que mejor todavía porque era una casa (...) Imagínate una casa para mí solo, grande, grande de dos pisos, todas las habitaciones libres, así que

8 De acuerdo con Cervio (2020) las denominadas villas de emergencia "son ocupaciones irregulares de tierra urbana vacante que se caracterizan por poseer una alta densidad poblacional. En general, presentan una trama irregular con acceso a las viviendas a través de pasillos, y el proceso de ocupación suele ser individual y diferido en el tiempo por parte de pobladores que conciben a la villa como una solución habitacional transitoria" (p. 344). En la CABA suelen ubicarse en sectores con accesibilidad a barrios centrales de la ciudad. 
dormía un día acá, dormía otro lado allá. Los primeros días era yo, miraba la tele, toda la película, tenía una sala de comedor, tenía un living, dos baños, tenía todo. Y así fui creciendo ahí en el hogar, ahí estudié, comencé a hacer los deportes, me anoté en scout, es como que hice mi vida ahí. (Mateo, 23 años, circo).

Las condiciones que llevan a Mateo a vivir en instituciones modifican la estructura familiar - se separa de sus padres y de sus 5 hermanos/as en esos años-, así como su cotidianeidad y entorno cotidiano. El aspecto edilicio, la distribución de los ambientes y lo permitido o prohibido ponen de manifiesto que el espacio institucional es rememorado, al mismo tiempo, como una "cárcel" y una "casa". En ese tránsito, la experiencia de habitar se identifica, de todos modos, como una vivencia positiva asociada al pasar de la villa y llegar a lo que reconoce como una "casa".

Si bien se han destacado las consecuencias negativas de las movilidades residenciales en las biografías juveniles, tales movilidades pueden permitir a las familias, y a las personas jóvenes en particular, mejorar sus condiciones de vida al salir de barrios vulnerabilizados y contar con mayor acceso a instituciones y recursos de calidad en salud, educación o recreación a los que difícilmente podrían acceder de otra manera (Buckle, 2017; Perkins, 2016). Tras salir de la institución ante su mayoría de edad, con escasos recursos, Mateo retorna a la casa de su madre en la villa. En su relato, sus significaciones acerca de la localización del hogar, en el barrio de Caballito, refuerzan el contraste entre las dificultades de la vida en la villa - durante su niñez y en la actualidad - "donde no hay muchas opciones (...) se pasa todo mucho por la droga, se pasa mucho por el alcohol, por el robo. Se pasa mucho por la muerte. En cambio vas afuera y pasa todo lo mismo, pero muy poco", frente a la posibilidad de vivir en una "casa", situada por "afuera" donde hay otras formas de hablar, de vestirse y hasta más "respeto", aspectos valorados por él.

Las dificultades del acceso al suelo urbano que enfrentan los sectores de menores ingresos en la RMBA, y en la CABA en particular, plantea la necesidad de habitar áreas y espacios precarizados, como las villas, o bien, hoteles-pensión ubicados en zonas centrales de la ciudad que facilitan, por ejemplo, el acceso a servicios y a fuentes de trabajo. En algunos casos toman la forma de falsos hoteles. Edificaciones preca- 
rias donde se alquilan habitaciones o camas, de tamaños reducidos y con escasos espacios comunes (Boy et al., 2015; Toscani, 2018).

Fatu, de 18 años, viajó de Paraguay a la CABA. Junto con dos hermanos, su madre y su padastro, al llegar alquilan una habitación en un barrio cercano al centro de la ciudad, de alta circulación y actividad comercial. Juan, de 21 años, viaja a esta ciudad a sus 12 años. En compañía de su familia alquila una habitación en el mismo barrio al que llega Fatu inicialmente. Gran parte de quienes residen en hotelespensiones son migrantes de países de la región, población que suele ser estigmatizada por marcas corporales étnico-raciales y por habitar en tales establecimientos (Boy et al., 2015). En los casos de Fatu y Juan, por razones inesperadas se ven obligados a mudarse:

Ni bien vine de Perú, y ahí (...) nos fuimos porque... supuestamente el edificio donde estábamos estaba siendo alquilado, viste, y, no, no estaba siendo alquilado, estaba siendo tomado. (Juan, 21 años, bachillerato).

Yo estuve viviendo en Once hasta que (...) el edificio lo (...) lo derrumbaron, lo tiraron. Y bueno, no teníamos dónde ir y mi tía que vive acá [villa en CABA] también en el barrio, hace mucho, ella es más primera que todas, digamos (...) Ella nos dio un pedazo de terreno ahí, que estaba vacío. Y bueno, nosotros hicimos ahí nuestra casa, que era una casilla. (Fatu, 18 años, bachillerato).

Tanto las condiciones edilicias deficitarias y el hacinamiento que caracteriza a estos espacios, como la informalidad de la contratación, generan gran inestabilidad. Ante la precariedad de los hoteles donde residían y la imposibilidad de continuar allí, estos jóvenes debieron salir repentinamente a la búsqueda de un nuevo lugar. En el caso de Juan, continuó viviendo en más de un hotel de la ciudad, hasta llegar a una de las villas de la ciudad un barrio vulnerabilizado, en la que también vive Fatu actualmente. En ambos casos, a partir de la toma ${ }^{9}$ de tierras, contarán con un suelo donde construir una casa propia. Cotton y

9 De acuerdo con Rodríguez et al. (2018) "La toma de tierras y la consolidación de villas y asentamientos es un proceso social — no estatal — de producción de origen no mercantil de la provisión de bienes urbanos necesarios para la vida, que ha caracterizado históricamente el proceso de crecimiento y desarrollo de las ciudades latinoamericanas" (p. 130). 
Schwartz-Barcott (2016) identifican entre las familias de bajos ingresos que los problemas con dueños de las viviendas, el deterioro de estas y violencias sociales y familiares son los motivos que impulsan las relocalizaciones continuas, generando condiciones cuasi-permanentes de inestabilidad residencial.

\section{Movilidades residenciales buscadas}

En las experiencias migratorias de los y las jóvenes y sus familias, el arribo a la RMBA, entre la última década del siglo XX y los primeros años del 2000, estuvo marcado por múltiples transiciones entre diferentes ciudades - de países de la región u otras provincias argentinas- y al interior de estas. Solanch, de 20 años, participante del circo, siendo niña viaja con sus padres a Buenos Aires desde Caacupé (Paraguay). Esta llegada no supuso la instalación definitiva o un corte en su vínculo con su país. Desde su primer año de vida, y por al menos dos años, el lugar de residencia de la familia se alterna entre Argentina y Paraguay “En Caacupé estuve un año viviendo todo el tiempo. Después íbamos dos, tres meses para allá, dos, tres meses acá y era así".

Victoria, de 18 años, vive actualmente en una casa propia en el GBA junto con sus hermanas, su madre y padre. En su caso, también optaron por viajar a Argentina desde Paraguay "primero vino mi papá, después mi mamá". Su hermana mayor nació allá, mientras que ella y su hermana menor lo hicieron en la RMBA. En su relato describe que cada año "dependiendo del presupuesto" viajan a Paraguay "para visitar a la abuela y a nuestros parientes".

Nociones como la migración cíclica o de retorno se utilizan para referirse a diferentes movimientos en los procesos migratorios. No obstante, los abordajes sobre movilidades residenciales tendieron a analizar estos desplazamientos como eventos únicos, con un origen y una llegada. Coulter et al. (2015) señalan la importancia de casos como la residencia itinerante, en la que niños y jóvenes cuyos padres/ madres no conviven mantienen dos o más residencias simultáneas en las que habitan cotidianamente. Para Solanch y Victoria, llegar a la RMBA, tras el cruce de las fronteras nacionales, no supuso un establecimiento final y definitivo. En ambos casos, movimientos dentro de la RMBA y hacia Paraguay, se suceden desde ese momento y hasta la actualidad. 
Los recorridos de quienes habitan en barrios populares de la RMBA suelen incluir experiencias migratorias con trayectorias de inestabilidad habitacional. En estos procesos, la localización de la vivienda se vuelve relevante (Di Virgilio y Gil y de Anso, 2012). En lo narrado por las y los jóvenes los desplazamientos se orientan en dos sentidos: la localización de las viviendas — asociadas a su potencialidad de acceso a escuelas y trabajo- - y el interés por conseguir una casa propia. Iván, de 24 años, participante del circo, vive con su familia en Villa Pompeya (CABA). Al iniciar la entrevista se presentaba como "Iván. Que nací en Salta. Me mudé acá cuando era chico, bah yo no me mudé, vinieron mis viejos. Y que tuvimos una vida bastante (...) mudándonos de un lugar a otro".

En su relato las transiciones entre distintas provincias argentinas y en el interior de la RMBA provocan en su niñez diversas experiencias, como convivir con su abuela o un tío, debido a que sus padres no podían sostenerlo económicamente "tengo los recuerdos de los lugares que fui (...) y que como te decía que yo crecí sin otras familias así alrededor de mi familia, como yo era grande, era el primero y jugaba solo" (Iván). Estos movimientos lo llevaron a vivir en diferentes tipos de vivienda y de tenencia diversas: de vivir en un "galpón”, pasando por alquilar diferentes inmuebles, hasta lograr comprar una casa. Supuso, además, cambios constantes de escuela, estar a cargo del cuidado de sus hermanos menores y sentir obligaciones aún siendo niño. Frente a la soledad y a las dificultades experimentadas, en las entrevistas de Iván estas diferentes (in)movilidades son nombradas como búsquedas continuas y necesarias que sus padres realizaron para mejorar las opciones, presentes y futuras, que a nivel económico, educativo o laboral, deseaban para la familia, entre ellas tener una vivienda propia.

Sánchez Estévez (2013), en una investigación de carácter etnográfico, realizada en la Ciudad de México, indaga las significaciones de la casa y las distintas experiencias de habitar en dos grupos sociales: a) familias de sectores medios-altos y b) familias que participan de una organización social popular. En el primer grupo, tener casa propia representa una búsqueda de oportunidades, un proceso de superación personal y progreso social, entendido como un valor a transmitir a sus hijos. En el segundo, la casa propia es percibida como producto del pasado, de un recorrido con sufrimiento, sostenido por vínculos fami- 
liares y colectivos, que resulta en felicidad en el presente. En el caso de Iván, la vivienda propia produce significaciones asociadas, al mismo tiempo, a un recorrido doloroso, solitario y sacrificado para él siendo niño, pero también a una valoración positiva del ahorro y el trabajo que sus padres realizaron para superarse y buscar mayor bienestar, expresado en la casa propia.

Edrul, de 19 años, vive en un barrio del sur de la CABA con su madre y hermanos. Su padre falleció un año antes de realizar la entrevista. Este había realizado el primer viaje a Argentina desde Bolivia con el interés de traer luego a su familia. Instaló un taller textil, actividad que ya desarrollaba en Bolivia, en una villa de la ciudad. En lo relatado, el joven señala que se sucedieron varias "mudanzas" dentro de la villa y hacia afuera del barrio, ya que el interés de su padre era "ir saliendo":

fue como una serie de cambios. Fueron cambios, pero con respecto siempre a buscar, digamos. Sí, mi viejo trataba de buscar un mejor lugar para nosotros (...) Por ejemplo, en la villa eran muy chicas las habitaciones, temas de cuestión con el ambiente y esas cosas (...) Y esos cambios fueron... cada vez nos íbamos alejando, digamos, de la villa. (Edrul, 19 años, circo).

Los distintos movimientos procuraban mejorar el tipo de vivienda, instalar el taller y salir de la villa. Para Edrul, si bien vivir en ese espacio presenta cierta peligrosidad, también connota otros sentidos. Ante dicha salida, rememora:

para mí no fue un cambio significativo porque yo a los chicos los seguía viendo por un tiempo, porque no me mudé a otro barrio, estaba a dos cuadras, y era habitual que con mi familia salíamos a comer ahí en la villa, en los lugares, en la feria, comprar cosas, era común. (Edrul, 19 años, circo).

En los abordajes de las movilidades residenciales que se centran en los efectos de las características de los barrios vulnerabilizados en la vida de los y las jóvenes se resaltan las consecuencias negativas que tiene el crecer en este tipo de ambientes (Goldsmith et al., 2016). No obstante, la experiencia de habitar estos barrios produce diferentes significaciones. En el caso de Edrul aparece asociado a un lugar de encuentro significativo para la sociabilidad familiar, que se sostiene incluso residiendo fuera de los límites barriales. 
Las movilidades residenciales no se limitan a experiencias basadas en largas distancias o cambios entre barrios, sino a las significaciones y prácticas que se construyen en torno a las distancias-cercanías (Cresswell, 2010). El cambio en el tipo de vivienda también resulta una experiencia que transforma lo residencial y la cotidianeidad. Mariana, de 18 años, participante del circo, describe que ha vivido toda su vida en la Villa 15 (CABA), junto a su hermana, su padre y su madre. Comparte el barrio con abuelos, tíos y primos. "Mi casa es una pasarela", destaca, haciendo referencia a que no solo viven cerca, sino que sus familiares transitan habitualmente por su casa.

Por los robos producidos en su sector, sus padres optaron por mudarse dentro de la villa a otra vivienda en un terreno cercano al de su abuelo. Allí también residían otros familiares "un terreno con tres casas, tres familias". Tras la propuesta de una organización barrial, sus familiares aceptan derribar sus casas para la construcción de edificios "vos le dabas la casa y ellos te daban el departamento". De acuerdo con Mariana, esto permitiría que más personas vivieran en un mismo terreno. Sin embargo, para ella "dos pasos de diferencia" marcan una "gran diferencia" en su vida cotidiana:

[¿Qué te pareció a vos ese cambio?] ¡No me gustó para nada! Yo directamente no me quería mudar porque donde vivíamos antes, o sea, son dos pasos de diferencia, ¿no? pero es una gran diferencia porque pasar de vivir a una casa a un departamento es complicado. Encima era una casa gigante, tenía un patio adelante, uno atrás y otro al costado. Había tres casas y encima estábamos por construir arriba. Lo que sí, a veces, compartíamos el baño y la cocina, entonces, como que llevó a pensarse más en los adultos que en los chicos. De que los adultos querían tener su espacio y los chicos no (...) como que pensaron más en ellos que en otra cosa. Los chicos dejaron, o sea, nosotros dejamos de jugar en el patio para ir a jugar a una pieza en el departamento ¿entendés? Complicado... y en el departamento tampoco te podés poner una pileta, ni podés hacer nada. (Mariana, 18 años, circo).

Kim y Smets (2020) analizan cómo las personas refugiadas en Amsterdam pueden crear un hogar en una nueva ciudad. Destacan que la experiencia de habitar el hogar requiere observar tanto las dimensiones materiales, asociadas a elementos visibles, físicos y tangibles, 
como las inmateriales, vinculadas con lo emocional y los elementos sociales y culturales. Para Mariana se expresan diferencias significativas entre vivir en una casa o en un departamento, sobre la base de sus características y posibles usos. Según la joven, el interés de las personas adultas al habitar sus hogares se relacionaba con la posibilidad de no compartir ambientes como el baño y la cocina. Mientras que para las y los niños su habitar se vinculaba con el juego y el uso recreativo de ambientes como un patio abierto. Será finalmente el habitar adulto el que prevalece por sobre el infantil al momento de decidir los cambios de vivienda.

\section{Movilidades residenciales imaginadas}

Las condiciones económicas familiares de Lulú y Elías llevarían a un posible cambio de residencia para el año 2021. Ambos estudian en la escuela secundaria de la CABA. Como se mencionó, Lulú vive en un departamento alquilado de Caballito, CABA. Recientemente, su madre obtuvo un crédito hipotecario que le permitió comprar un terreno en una localidad del GBA, donde están construyendo una casa. Para Elías (18 años) y su familia, las dificultades para pagar el alquiler del departamento donde viven impulsan un posible traslado hacia la ciudad donde nació su madre y que visitan constantemente. Estas situaciones se presentan en un momento singular para estos jóvenes: la finalización de la escuela secundaria y una posible inserción en la universidad.

Lulú y Elías describen estas movilidades residenciales como proyectos a efectivizarse en un futuro cercano. Sin embargo, imaginan otros recorridos posibles no determinados por las proyecciones de sus padres: la posibilidad de no mudarse e iniciar la universidad en una institución cercana como sugiere Lulú o de "independizarse" y quedarse en la ciudad como expresa Elías, "si tengo la suerte de poder independizarme y quedarme, lo voy a hacer”. Ansell y van Blerk (2005), en un estudio realizado en Lesotho y Malawi, África, recuperan las voces de niños y niñas que atravesaron múltiples movilidades residenciales y migratorias para destacar las experiencias de habitar infantiles, sus usos de las viviendas y los espacios urbanos. Frente a la informalidad y alta movilidad, los deseos a futuro no se asocian con mejores características materiales de las viviendas, sino con la posibilidad de contar con una casa propia y estable. 
Las y los jóvenes mencionan tres situaciones esperadas que se vinculan entre sí y que manifiestan formas de habitar imaginadas: "salir" del barrio en el que residen - especialmente entre quienes viven en villas-, tener un lugar propio e individual y que integrantes de su familia también cuenten con una vivienda propia.

Ante las opciones se destaca tener "mi propio departamento", como afirma Chinita. Una joven de 20 años, que asiste al circo, vive en la villa 21-24 (CABA) y estudia Psicología en una universidad privada con una beca que obtuvo a través de una iglesia católica del barrio. Omar, de 20 años, también participaba en el circo. Él fue echado del hotel donde convivía con su madre, con quien no tenía una buena relación. Al momento de la entrevista, no estudiaba y tenía empleos informales. Transitaba entre casas de amigos y paradores para varones en situación de calle. Ante un posible futuro menciona "yo quisiera tener... mi casa solo y ya está".

La potencialidad de acceder a una vivienda propia se asocia, sin embargo, a terminar los estudios secundarios y conseguir un trabajo. Sofía, 18 años, también anhela tener una casa propia. Para ello, consideraba necesario:

Tener el título, tener un buen laburo, después bueno, haberme ya mudado de donde vivo, o sea, que mi mamá tenga, o sea, comprarle una casa a mi mamá, que tenga su casa y yo mudarme a mi casa. (Sofía, 18 años, circo).

Arancibia (2016) señala que los y las jóvenes de sectores populares de la RMBA enfrentan mayores limitaciones para acceder a una vivienda propia. En el caso de las y los entrevistados se imaginan dicho acceso en un futuro no tan lejano que aparece asociado a esfuerzos personales y a lo logrado, en algunos casos, por sus propios padres. Para Sofía, obtener un título universitario y un buen trabajo le permitirá una vivienda propia fuera del barrio, Bajo Flores (CABA), pero también conseguir una vivienda para su madre.

\section{Discusión y conclusiones}

A partir de las entrevistas con jóvenes de barrios populares de Buenos Aires, las movilidades residenciales surgieron como procesos relevantes en sus vidas. De las significaciones en torno a estas emergieron ca- 
tegorías que se identificaron como movilidades forzosas, buscadas e imaginadas.

Estas movilidades pusieron de manifiesto desigualdades sociales y limitaciones que plantean los espacios urbanos para estos grupos sociales. Sin embargo, no es posible comprender tales procesos solo desde las posiciones sociales, las inserciones territoriales o lo etario.

Como señalé, distintos estudios destacan las transformaciones sociales de los últimos años caracterizadas por una singularización de las sociedades, que interpela a las ciencias sociales y a sus modos de abordar lo social. Es preciso, en consecuencia, atender a las experiencias, reflexividades y al trabajo que los actores deben llevar adelante para construir el mundo social y constituirse a sí mismos como individuos.

A su vez, entender a las personas jóvenes como actores completos y activos visibiliza sus experiencias actuales no como simple preparación o paso hacia la adultez, sino como generadoras de prácticas y significaciones propias acerca de lo que consideran hogar en las intersecciones entre movilidades e inmovilidades que atraviesan sus biografías.

En el análisis de las movilidades residenciales, la noción de experiencia permite entrever cómo se enfrentan los mecanismos sociales impuestos por las lógicas urbanas neoliberales y la profundización de desiguales condiciones de vida, pero también los intersticios en los que las y los jóvenes y sus familias buscan crear hogares y vidas posibles.

Tales mecanismos generan que las movilidades de familias con bajos recursos se vean impulsadas por a) condiciones económicas, relacionadas con el tipo de vivienda posible de pagar; b) las condiciones de seguridad y violencia familiar, edilicia, urbana; y c) las condiciones sociales vinculadas con situaciones conflictivas con administradores de hoteles-pensiones o las transformaciones al interior de las familias a partir de separaciones o divorcios.

Se destacan las múltiples violencias en las vidas de las y los jóvenes relacionadas con lo familiar y lo urbano. Estas provocan la salida del hogar de diferentes integrantes de las familias, incluso de los propios jóvenes, hasta la exposición a entornos inseguros y precarios. Tales situaciones se intersectan con dificultades económicas de las familias 
y la informalidad de los tipos de vivienda a los que logran acceder en función de los costos y los propios ingresos.

Estas violencias no son nombradas por los y las jóvenes como condiciones sociales injustas, sino que se asocian a problemáticas familiares privadas que, aun con intervención de instituciones sociales, se presentan como situaciones provocadas y resueltas desde lo personal. A su vez, incluso reconociendo esas situaciones como negativas, las movilidades son percibidas como oportunidades para nuevas experiencias ligadas a una mejora en el ámbito familiar, al tipo de vivienda en la cual vivir o al tipo de actividades o recursos a los que se acceden.

En lo buscado son las estrategias de las personas adultas de la familia las que son percibidas como acciones que posibilitan los desplazamientos y la obtención de una vivienda propia, objetivo valorado por las y los entrevistados. En los recorridos para conseguir mejores condiciones de vida, reconocen el trabajo que realizan sus padres/madres. Sin embargo, también se consideran ellos mismos como parte de tales estrategias al sostener desde sus lugares de hijos prácticas como el cuidado de hermanos menores, las tareas hogareñas o simplemente aceptando lo dispuesto por los adultos. Aunque ello provoque sufrimiento o nostalgia, las y los entrevistados priorizan el esfuerzo y las posibilidades que esas movilidades pueden generar en sus propias vidas presentes y futuras.

Salir de los barrios en los que habitan actualmente se presenta en la intersección entre lo buscado y lo imaginado. Esto se sitúa entre las realidades de inseguridad vividas y las visiones estigmatizantes acerca de estos barrios a las que estos jóvenes están expuestos constantemente. Para algunos la llegada a barrios como las villas habilita el acceso a un terreno propio. Para otros, cambiar a un lugar al que se considera socialmente mejor no implica necesariamente una experiencia positiva. En relación con sus prácticas cotidianas, por ejemplo las asociadas a la sociabilidad y a lo recreativo, el lugar de residencia se valora en función de mantener estos espacios, más que en las características de los barrios o de las viviendas. Aunque pueda independizarse de los proyectos de sus padres/madres, al indagar (in)movilidades imaginadas el mantenimiento de la residencia actual y permanecer en el barrio aparece más asociado a elegir el lugar de residencia que a buscar mayor autonomía familiar. 
Las potencialidades de la imaginación para producir subjetividades y la capacidad de aspirar permiten entrever un rango de vidas posibles que, si bien se encuentran atravesadas por condiciones sociales, etarias, de género o étnico-raciales, no están determinadas a priori por ellas (Appadurai, 2004 en Tsao et al., 2018). Para las y los entrevistados, incluso viviendo en condiciones precarias o con dificultades, la opción de tener una vivienda propia no solo se vislumbra como posible solo desde lo imaginado, sino desde la propia experiencia que han atravesado junto con sus familias, donde este objetivo ha podido ser alcanzado. Lo significativo es que esto se imagina como recorridos individuales, sustentados en esfuerzos personales y siguiendo pautas sociales esperadas para las personas jóvenes, lo que supone trabajar en empleos considerados estables, estudiar en la universidad y conformar una familia propia.

Hablar de movilidades residenciales no supone distancias preestablecidas. Incluso viviendo en el mismo barrio, la transformación de las características edilicias de la vivienda, como el paso de una casa a un departamento, puede significar un cambio importante en las vivencias cotidianas. Contar con un espacio abierto como un patio o ambientes más grandes se relacionaron con prácticas vinculadas a la niñez y a las juventudes, donde lo recreativo y lo lúdico tienen prioridad. Sin embargo, no son consideradas de esa forma por los adultos de las familias, o bien, por las instituciones que desarrollan proyectos habitacionales para sectores de bajos recursos.

En definitiva, las características de los barrios o las motivaciones que llevaron a realizar desplazamientos o permanecer en cada lugar no determinan los procesos de movilidad residencial y lo que esto significa para estos jóvenes. Aun tratándose de experiencias compartidas con otros integrantes de sus familias, se generan otras emociones, significaciones y prácticas que es preciso considerar tanto al momento del análisis de estos procesos, como en el desarrollo de políticas vinculadas con la vivienda y la producción y usos de los espacios urbanos.

\section{Referencias}

Ansell, N. y van Blerk, L. (2005). "Where We Stayed was very Bad...": Migrant children's perspectives on life in informal rented ac- 
commodation in two Southern African cities. Environment and Planning A, 37(3), 423-440. https://doi.org/10.1068/ a36226

Araujo, K. y Martuccelli, D. (2010). La individuación y el trabajo de los individuos. Educação e pesquisa, 36(SPE), 77-91. https://doi. org/10.1590/s1517-97022010000400007

Araujo, K. y Martuccelli, D. (2011). La inconsistencia posicional: un nuevo concepto sobre la estratificación social. Revista $C E-$ PAL, (103), 165-178. https://doi.org/10.18356/20764528-es

Arancibia, M. (2016). Trayectorias habitacionales de las y los jóvenes: construir un hogar propio en el área metropolitana de Buenos Aires entre 1999 y 2013. Última década, 24(44), 171-193. http://dx.doi.org/10.4067/S0718-22362016000100007

Baker, E., Pham, N. T. A., Daniel, L., y Bentley, R. (2019). How does household residential instability influence child health outcomes? A quantile analysis. International Journal of Environmental Research and Public Health, 16(21), 4189. https://doi. org/10.3390/ijerph16214189

Bastán, G. G. y Paulín, H. L. (2016). Identidades juveniles en escenarios de periferización urbana. Una aproximación biográfica. Quaderns de psicologia, 18(1), 35-52. https://doi.org/10.5565/ rev/qpsicologia.1307

Boy, M., Marcús, J., y Perelman, M. D. (2015). La ciudad y el encuentro de la diferencia. Adultos que viven en la calle y mujeres que habitan en hoteles-pensión. Ciudad de Buenos Aires, 2007-2011. Estudios demográficos y urbanos, 30(2), 369-404. http://www.scielo.org.mx/scielo.php?pid=S018672102015000200369\&script=sci_abstract

Brazil, N. y Clark, W. A. (2019). Residential mobility and neighborhood inequality during the transition to adulthood. Urban geography, 40(7), 938-963. https://doi.org/10.1080/02723638.2018. 1506614

Buckle, C. (2017). Residential mobility and moving home. Geography Compass, 11(5). https://doi.org/10.1111/gec3.12314

Cervio, A. L. (2020). Trayectorias de habitabilidad en contextos de segregación socio-espacial: una aproximación teóricometodológica desde las sensibilidades. Economía Sociedad y Territorio, 21(63), 335-364. https://doi.org/10.22136/ est20201544 
Charmaz, K. (2013). La teoría fundamentada en el siglo XXI: Aplicaciones para promover estudios sobre la justicia social. En N. Denzin e Y. Lincoln (Coords.), Manual de investigación cualitativa (pp. 270-325). Gedisa.

Charmaz, K. y Belgrave, L. (2012). Qualitative interviewing and grounded theory analysis. En J. Gubrium, J. Holstein, A. Marvasti, y K. McKinney (Eds.), The SAGE handbook of interview research: The complexity of the craft (pp. 347-365). SAGE.

Chaves, M. (2005). Juventud negada y negativizada: representaciones y formaciones discursivas vigentes en la Argentina contemporánea. Última década, 13(23), 9-32. https://doi. org/10.4067/s0718-22362005000200002

Chaves, M. (2013). Culturas juveniles en la tapa del diario: tensiones entre el margen y el centro de la hoja. En M. Chaves y E. Fidalgo (Comps.), Políticas de infancia y juventud. Producir sujetos y construir Estado (pp. 111-137). Espacio Editorial.

Chaves, M. y Segura, R. (Eds.) (2015). Hacerse un lugar: circuitos y trayectorias juveniles en ámbitos urbanos. Editorial Biblos.

Cosacov, N. (2015). Más allá de la vivienda: los usos de la ciudad. Movilidad cotidiana de residentes en Buenos Aires. Estudios Socioterritoriales, (18), 61-80. http://www.scielo.org.ar/scielo. php?script=sci_arttext\&pid=S1853-43922015000200005

Cotton, B. P. y Schwartz-Barcott, D. (2016). Residential instability among low-income families: A concept analysis. Archives of psychiatric nursing, 30(2), 257-261. http://dx.doi. org/10.1016/j.apnu.2015.11.006

Coulter, R., Ham, M. V., y Findlay, A. M. (2015). Re-thinking residential mobility: Linking lives through time and space. Progress in Human Geography, 40(3), 352-374. https://doi. org/10.1177/0309132515575417

Cresswell, T. (2010). Towards a politics of mobility. Environment and planning, 28(1), 17-31. https://doi.org/10.1068/d11407

De Sena, A., Lisdero, P., y Scribano, A. (2015). Caminos cualitativos: aportes para la investigación en Ciencias Sociales. Ciccus.

Di Leo, P. (2016). Violencias, sociabilidades y procesos de subjetivación: un análisis de sus vinculaciones en experiencias de jóvenes en tres ciudades de Argentina. Persona y Sociedad, 25(3), 55-78. https://bit.ly/30euiph 
Di Leo, P. F. y Camarotti, A. C. (Eds.) (2013). “Quiero escribir mi historia." Vidas de jóvenes en barrios populares. Biblos.

Di Virgilio, M. (2011). La movilidad residencial: una preocupación sociológica. Territorios, 2(25), 173-190. https://revistas.urosario.edu.co/index.php/territorios/article/view/1851

Di Virgilio, M. (2018). Construyendo una lupa para mirar la división social del espacio en la ciudad de Buenos Aires: la segregación residencial revisitada en diferentes escalas. Revista Iberoamericana de Urbanismo, 14(9), 59-78. https://raco.cat/ index.php/RIURB/article/view/351861

Di Virgilio, M. y Gil y De Anso, M. (2012). Estrategias habitacionales de familias de sectores populares y medios residentes en el área metropolitana de Buenos Aires (Argentina). Revista de Estudios Sociales, (44), 158-170. http://www.scielo.org. co/scielo.php?pid=S0123-885X2012000300015\&script=sci_ abstract\&tlng=es

Diógenes, G. (2020). Cidade, arte e criação social: Novos diagramas de culturas juvenis da periferia. Estudos Avançados, 34(99), 373-390. https://doi.org/10.1590/s0103-4014.2020.3499.022

Duarte Quapper, K. (2000). ¿Juventud o juventudes? Acerca de cómo mirar y remirar a las juventudes de nuestro continente. Última década, 8(13), 59-77. http://dx.doi.org/10.4067/S071822362000000200004

Dubet, F. (2013). El trabajo de las sociedades. Amorrortu.

Falkingham, J., Sage, J., Stone, J., y Vlachantoni, A. (2016). Residential mobility across the life course: Continuity and change across three cohorts in Britain. Advances in Life Course Research, (30), 111-123. https://doi.org/10.1016/j.alcr.2016.06.001

Felice, M. (2017). La "casa de la amistad": Modos de construir y significar el hogar propio en jóvenes de la Ciudad de Buenos Aires. Última década, 25(46), 117-146. http://dx.doi.org/10.4067/ S0718-22362017000100117

García, J. (1 de julio de 2013). Enfoque etnográfico y bachilleratos populares: negociaciones entre el tiempo escolar y la autogestión de los aprendizajes. X Jornadas de Sociología. Facultad de Ciencias Sociales, Universidad de Buenos Aires, Buenos Aires, Argentina.

Goldsmith, P., Pylman, M., y Vélez, W. (2016). Are there neighborhood effects on young adult neighborhood attainment? Evidence 
from mixed-logit models. Social Science Research, (64), 2542. https://doi.org/10.1016/j.ssresearch.2016.09.025

Goodman, A., Snyder, M., y Wilson, K. (2018). Exploring Indigenous youth perspectives of mobility and social relationships: A photovoice approach. The Canadian Geographer, 62(3), 314325. https://doi.org/10.1111/cag.12460

Hochstenbach, C. y Boterman, W. R. (2017). Intergenerational support shaping residential trajectories: Young people leaving home in a gentrifying city. Urban studies, 54(2), 399-420. https:// doi.org/10.1177/0042098015613254

Jirón, P. e Imilan, W. A. (2018). Moviendo los estudios urbanos. La movilidad como objeto de estudio o como enfoque para comprender la ciudad contemporánea. Quid 16: Revista del Área de Estudios Urbanos, (10), 17-36.

Kaufmann, V., Bergman, M., y Joye, D. (2004). Motility: Mobility as capital. International Journal of Urban and Regional Research, 28(4), 745-756. https://doi.org/10.1111/j.03091317.2004.00549.x

Kim, K. y Smets, P. (2020). Home experiences and homemaking practices of single Syrian refugees in an innovative housing project in Amsterdam. Current Sociology, 68(5), 607-627. https:// doi.org/10.1177/0011392120927744

Lara, D., Decker, M., y Brindis, C. (2016). Exploring how residential mobility and migration influences teenage pregnancy in five rural communities in California: Youth and adult perceptions. Culture, health \& sexuality, 18(9), 980-995. https://doi.org/1 0.1080/13691058.2016.1150514

Leclerc-Olive, M. (2009). Temporalidades de la experiencia: las biografías y sus acontecimientos. Iberofórum. Revista de Ciencias Sociales de la Universidad Iberoamericana, 4(8), 1-39. http://www.idaes.edu.ar/pdf_papeles/TEMPORALIDADES\%20DE\%20LA\%20EXPERIENCIA\%20Michele\%20 Leclerc-Olive.pdf

Martinic, R. y Stecher, A. (2020). Experiencias de trabajadores del retail en Chile. Aproximación desde la sociología de Dubet. Convergencia, (27), 1-31. https://doi.org/10.29101/crcs. v27i0.11939

Merlinsky, G. (2006). La entrevista como forma de conocimiento y como texto negociado. Cinta de moebio. Revista de Episte- 
mología de Ciencias Sociales, (27), 27-33. http://www.facso. uchile.cl/publicaciones/moebio/27/merlinsky.pdf

Metzger, M., Fowler, P., Anderson, C., y Lindsay, C. (2015). Residential mobility during adolescence: Do even "upward" moves predict dropout risk? Social science research, (53), 218-230. https://doi.org/10.1016/j.ssresearch.2015.05.004

Padilla, D. (2017). Un modelo conceptual para abordar las trayectorias residenciales de los jóvenes contemporáneos. Revista de Estudios de Juventud, (116), 11-29. http://www.injuve. es/sites/default/files/2018/06/publicaciones/revista116_ documentos1.pdf

Perkins, K. (2016). Reconsidering residential mobility: Differential effects on child wellbeing by race and ethnicity. Social Science Research, (63), 124-137. https://doi.org/10.1016/j.ssresearch.2016.09.024

Roberti, E. (2017). Hacia una crítica a la sociología de la transición: reflexiones sobre la paradoja de la desinstitucionalización en el análisis de las trayectorias de jóvenes vulnerables en Argentina. Estudios Sociológicos de El Colegio de México, 35(105), 489-516. https://doi.org/10.24201/ es.2017v35n105.1468

Rodriguez, F. y Dawkins, M. (2017). Undocumented Latino youth: Migration experiences and the challenges of integrating into American society. Journal of International Migration and Integration, 18(2), 419-438. https://doi.org/10.1007/s12134-016-0484-y

Rodríguez, M. C., Rodríguez, M. F., y Zapata, M. C. (2018). Mercantilización y expansión de la inquilinización informal en villas de Buenos Aires, Argentina. Revista INVI, 33(93), 125-150. http://dx.doi.org/10.4067/S0718-83582018000200125

Salazar, N. (2020). On imagination and imaginaries, mobility and immobility: Seeing the forest for the trees. Culture \& Psychology, 0(0), 768-777. https://doi.org/10.1177/1354067X20936927

Salazar, N. y Smart, A. (2011). Anthropological takes on (im)mobility. Identities, 18(6), i-ix. https://doi.org/10.1080/107028 9X.2012.683674

Sánchez Estévez, R. (2013). La significación de la casa y del habitar en dos grupos sociales en la Ciudad de México. Cuicuilco, 20(56), 77-94. http://www.scielo.org.mx/scielo.php?script=sci_ abstract\&pid=S0185-16592013000100005\&lng=es\&nrm=iso 
Schmitt, S. y Lipscomb, S. (2016). Longitudinal associations between residential mobility and early academic skills among lowincome children. Early Childhood Research Quarterly, (36), 190-200. http://dx.doi.org/10.1016/j.ecresq.2016.01.002

Segura, R. (2017). Desacoples entre desigualdades sociales, distribución del ingreso y patrones de urbanización en ciudades latinoamericanas. Reflexiones a partir de la Región Metropolitana de Buenos Aires. Revista CS, (21), 15-39. https://doi. org/10.18046/recs.i21.2278

Sheller, M. y Urry, J. (2006). The new mobilities paradigm. Environment and planning $A, 38(2), 207-226$. https://doi.org/10.1068/ a37268

Soto, M. (2017). Movilidad residencial estudiantil en áreas históricas metropolitanas: el caso del Área Metropolitana de Valparaíso (AMV). Revista Geográfica de Valparaíso, (54), 1-16. http://www.revistageografica.cl/index.php/revgeo/article/ view/18/17

Muñoz, V. y Ponce, C. (2019). Juventud y política en sociedades en cambio. Temas Sociológicos, (24), 9-22. https://doi. org/10.29344/07196458.24.1965

Tapia, S. A. (2016). Cuerpos, emociones e individuación: un análisis de las experiencias de jóvenes que realizan prácticas artísticas y deportivas en barrios populares de la Ciudad Autónoma de Buenos Aires (Tesis doctoral inédita). Universidad de Buenos Aires, Argentina.

Tønnessen, M., Telle, K., y Syse, A. (2016). Childhood residential mobility and long-term outcomes. Acta Sociológica, 59(2), 113129. https://doi.org/10.1177/0001699316628614

Toscani, M. (2018). Dinámica de los hoteles-pensión y los desalojos del barrio de Constitución. Aproximaciones desde la dimensión de poder. Quid 16. Revista del Área de Estudios Urbanos, (9), 139-152. https://publicaciones.sociales.uba.ar/index.php/ quid16/article/view/2892

Tsao, J., Hardy, I., y Lingard, B. (2018). Aspirational ambivalence of middle-class secondary students in Hong Kong. British Journal of Sociology of Education, 39(8), 1094-1110. https://doi. org/10.1080/01425692.2018.1456904

Urzúa Martínez, S. (2015). ¿Cómo marchan los jóvenes en el Chile de posdictadura?: Algunas notas acerca de la apropiación 
del espacio público y el uso político del cuerpo. Última década, 23(42), 39-64. http://dx.doi.org/10.4067/S071822362015000100003

Varela Huerta, A. (2015). "Buscando una vida vivible": la migración forzada de niños de Centroamérica como práctica de fuga de la "muerte en vida". El Cotidiano, (194), 19-29. https://www. redalyc.org/articulo.oa?id=325/32542592003

Vasilachis, I. (Coord.) (2012). Estrategias de investigación cualitativa. Gedisa. 